\title{
A Critical Realist Review of Pre-Registration Nursing Student Stress
}

\author{
Phil Coleman $^{1} \&$ Gillian Vance ${ }^{2}$ \\ ${ }^{1}$ School of Health, Wellbeing \& Social Care, Faculty of Health, Wellbeing \& Language Studies, The Open \\ University, Milton Keynes, United Kingdom \\ ${ }^{2}$ School of Medical Education, Newcastle University, United Kingdom \\ Correspondence: Phil Coleman, Staff Tutor/Senior Lecturer, School of Health, Wellbeing \& Social Care, Faculty \\ of Wellbeing, Education \& Language Studies, The Open University, Milton Keynes. MK7 6AA. United \\ Kingdom.
}

Received: May 9, 2020

Accepted: June 15, 2020

Online Published: June 28, 2020

doi:10.20849/ijsn.v5i2.748

URL: https://doi.org/10.20849/ijsn.v5i2.748

\begin{abstract}
This Critical Realist review recognises the transitional challenge faced by all undergraduates on their path to becoming qualified practitioners but draws attention to the particularly high levels of student stress associated with the experience of learners who enrol on pre-registration nursing programmes. It also examines international evidence of factors which contribute to such stress. Professional opinion, reports, qualitative, quantitative and mixed methods research is thematically presented to indicate the wide range of educational, social, environmental, intrapersonal and interpersonal variables that contribute to pre-registration nursing student stress. Congruent with the principles of Critical Realism, the paper also identifies several emerging fields associated with student nurse stressors that are worthy of further investigation due to an apparent paucity of published work. Finally, the authors briefly highlight their own research activity currently underway to extend the body of knowledge in these areas and in so doing seek to help address student retention issues within nursing.
\end{abstract}

Keywords: critical realism, stress, burn-out, nursing students, nurse education

\section{Introduction: The Magnitude and Prevalence of Nursing Student Stress}

It has been widely recognised for many years that becoming a graduate nurse is a complex and stressful process and one for which many students feel inadequately prepared (Newton \& McKenna 2007, Boychuk Duchscher 2009, Alzayyat \& Al-Gamal 2014) and, globally, nursing currently faces a growing practitioner shortage (Pront, Kelton, Munt \& Hutton 2013, Flott \& Linden 2016). O'Donovan, Doody and Lyons (2013. p.969) comment that 'it is difficult to find agreement among those who are expert in the area regarding a concise definition of stress. In the United Kingdom [UK], however, the Health and Safety Executive (2020) broadly but concisely describe stress as 'the adverse reaction people have to excessive pressures or other types of demand placed on them'. The physical and emotional demands associated with providing nursing care may cause some practitioners to be unable to adopt effective and healthy coping strategies and thereby have adverse consequences on their health and wellbeing (Laal \& Aliramaie 2010, Shaban, Khater \& Akhu-Zaheya 2012, Labrague 2013). Since nursing programmes today impose greater expectations on students (Timmins, Corroon, Byrne \& Mooney 2011), it has become even more important that such curricula are designed to facilitate positive stress management and effectively prepare students to enter the nursing workforce (Fornés-Vives, Garcia-Banda, Frias-Navarr \& Rosales-Viladrich 2016).

The transitional challenge faced by students on their path to becoming qualified practitioners is not unique to nursing; for example, similar difficulties have been described in medicine (Rahmann et al 2014, Kuhlmann, Huss, Burger \& Hammerle 2016, Weurlander et al 2018), physical therapy (Higuchi \& Echigo 2016, Tambag \& Can 2018, Siddiqi et al 2019), occupational therapy (Govender, Mkhabela, Hlongwane, Jalim, \& Jetha 2015, Golos \& Tekuzener 2019) and within primary and secondary teaching (Malderez, Hobson, Tracey \& Kerr 2007, Stricklin \& Tingle 2016, Ord \& Nuttall 2016). Nevertheless, research in the United States of America found that 'nursing students reported higher stress scores on academic and external stresses' than students of dentistry, medicine, pharmacy or physical therapy (Stecker 2004, p.469) and it continues to be argued that 'nursing students experience higher levels of stress than students in other health sciences' (Rafati, Nouhi, Sabzevari \& Dehghan-Nayeri 2017). In the Republic of Ireland, a study involving 348 PRN students by Timmins et al (2011) 
found that 10 percent of PRN students reported using alcohol or drugs to relieve stress and less than 69 percent of respondents rated their mental health as 'good' or better.

A recent survey of pre-registration nursing [PRN] students at a university in the UK indicated stress and concerns regarding the competing demands of academic workload and clinical placements within their programme. Moreover, respondents reported frustration, a sense of inadequacy and considered withdrawing from their programme (Cust 2020). Although there is 'no central record of student nurse attrition in the UK and no standardised method of recording it' (Urwin et al 2010, p.203), it has been estimated that 'the average attrition rate for student nurses in England is 20\%' (Boath et al 2016, p.81) and in some universities may be as high as 25 percent (Willis 2015). More recent research by Buchan, Charlesworth, Gershlick and Seccombe (2019) reported that PRN student attrition was as high as 50 percent in some UK universities, but as low as 5 percent in others. It seems reasonable to assume that excessive stress may be a contributory factor in these high levels of withdrawal from PRN programmes in this nation.

Longitudinal research involving 1,702 nursing students in Sweden throughout their PRN programme found that study burn-out increased from 30 percent in the first year to 41 percent by the third year and levels of exhaustion and disengagement also showed a statistically significant increase as the students' course progressed. The researchers therefore concluded that 'study burn-out may have interfered with learning and psychological well-being' (Rudman \& Gustavsson 2012, p.988). Furthermore, evidence indicates that Registered Nurses [RNs] often leave the discipline within a year of qualification as a result of excessive stress and burn-out (Health Education England 2015, Flott \& Linden 2016); a phenomenon first recognised over four decades ago and originally referred to as 'reality shock' but more recently termed 'role transition' (Sparacino 2015). This paper offers a Critical Realist review of some of the key factors associated with PRN student stress and identifies areas worthy of further investigation if nursing is to effectively achieve higher levels of student retention on PRN programmes.

\section{Critical Realism and the Literature Search and Review}

Critical Realism, also termed Neomodernism (Parpio, Malik, Punjani \& Farooq 2013), Transcendental or Complex Realism (Clark 2008), was developed in the late 1970s by the UK philosophers Roy Bhaskar and Rom Harré (Bhaskar 2008) and more recently has gained 'prominence as an alternative research framework particularly in the social sciences but also in nursing' (Terry 2013, p.62). Briefly, this philosophy asserts that, although an objective reality exists (Williams, Rycroft-Malone \& Burton 2016), the world is 'composed not only of events, states of affairs, experiences, impressions and discourses but also underlying structures, powers and tendencies' (Patomaki \& Wright 2000, p.223) much of which it is impossible for any individual to observe (McEvoy \& Richards 2006). Moreover, according to Critical Realists, since the way all human beings perceive the world is implicitly shaped by their social and cultural experiences, researchers can never be wholly objective (McGhee \& Grant 2017) and so whilst science must rely on the development of robust socially produced theories, it also needs to recognise that such theories are always unavoidably limited and potentially imperfect (Bergin, Wells \& Owen 2008).

Modern nursing practice and therefore nurse education is 'embedded within complex social situations' (Williams, et al 2016, p.1). Critical Realism supports an epistemological and methodological approach to exploring a topic in which a researcher can legitimately capture a diverse range of evidence, provide deep explanations (Shajimon \& Soon-Chean 2018) and judge the situation investigated (Clegg 2005). Ultimately, Critical Realist research should also seek to implement positive change (Parlour \& McCormack 2012) and reach 'reasoned conclusions about how organizations and practices should be' (Edgley, Strickley, Timmons \& Meal 2016, p.326). Critical Realism therefore appears a particularly relevant philosophical framework within which to undertake investigations associated with complex, socially embedded, practice-based fields such as nurse education.

Enquiry based activities undertaken from a Critical Realist perspective seek to establish generalisations based on the most plausible explanations presented in accordance with the available evidence (Bisman 2010). Rather than demonstrating objectivity, Critical Realists strive to present an evidence-based case which leads the reader through their arguments whilst referring to the supporting literature and in so doing facilitate third-party evaluation of their assertions (Edgley et al 2016). Unlike a traditional systematic review [more closely aligned to Positivist philosophy] which collates the number of 'quality' [most commonly quantitative], studies that support or challenge a hypothesis (Clegg 2005), a Critical Realist review has a more flexible structure which seeks to capture and organise values, in the form of ideas, theories and logic, into a coherent argument (Edgely et al 2016) and indicate areas worthy of further study (O'Mahoney \& Vincent 2014). This is because the fundamental purpose of a Critical Realist review is to stimulate questions rather than provide answers (Edgely et al 2016). 
Resources included within this paper are international, but limited to work published in English and were drawn from a range of databases including Academic Search Complete, BioMed Central, the British Library EThOS resource, CINAHL with Full Text, the Directory of Open Access Journals, Emerald Premier, Google, Google Scholar, Internurse, OvidSP Journals, PubMed, Sage Journals Online, Taylor \& Francis Journals Online and university library texts. Key search terms were generated following professional discussions with academic colleagues involved in the delivery of both PRN programmes and other professional education courses and included: 'attrition', 'burn-out', 'coping', 'nursing', 'placement', 'practicum', 'stress' and 'student'. Boolean operators, lemmatization and field options were also employed to optimise and focus the search in respect of PRN student experience. All research studies included in this paper were exposed to the same evaluation process, based upon the criteria proposed by Bonine and Oh (2006). Congruent with Critical Realist philosophy, however, evidence utilised within the review is not simply restricted to research findings; pertinent reports and professional opinion are also recognised. Furthermore, qualitative, quantitative and mixed methods research are assigned equal status within the academic argument.

\section{Stress Factors in Academic and Practice Learning}

A systematic review by Alzayyat \& Al-Gamal (2014) identified that relations in the clinical environment, caring for patients and families and academic demands were the highest reported stressors for nursing students. In addition, a quantitative study by Burnard et al (2008, p.138) which generated data from a questionnaire completed by 1,707 PRN students based in five countries identified that 'stress in nursing is a global issue'. These researchers, however, also reported variation in whether the clinical or academic demands of a nursing programme were deemed most stressful; students in Albania, the Czech Republic and Wales reported that both elements of the programme were equally challenging, whilst those in Brunei and Malta found the academic study more demanding. A further comparative study of stress amongst a sample of 547 nursing students in Greece, Nigeria and the Philippines also highlighted variation in the nature and degree of stress reported by students. Nevertheless, respondents from all three nations still ranked academic work, stress from faculty and staff and the clinical environment as amongst the overall highest stressors (Labrague et al 2018).

In Jordan, completion of a self-reported questionnaire by 181 second year undergraduates at two universities rated completing assignment work and experience in the clinical setting as the most stressful components of their PRN programme. Specifically, respondents cited over-assessment and an excessive study workload as problematic, but the authors additionally concluded that it seemed clinical placements were often neither welcoming nor desirable locations for nursing students (Shaban, Khater \& Akhu-Zaheya 2012). A survey in the Philippines involving 61 third and fourth-year nursing students also found the greatest stressors identified by students were assignments and workload but that a perceived lack of competency was reported as a major source of learner stress during placements (Labrague 2013).

By enabling students to develop and apply essential clinical skills, the practicum has been described as a critical component of all PRN programmes (Madhavanpraphakaran, Shukri \& Balachandran 2014, Chan, Tang, Choi, Liu \& Taylor-Pilae 2018). Research, however, suggests that nursing students commonly regard clinical learning as one of the most stressful parts of their education (Timmins et al 2011) and therefore adverse placement experiences may be a key risk factor in student attrition. Given that some PRN student placements may only be of two to four weeks duration and it may take the learner at least the first week to settle into the experience, the importance of familiarising students with the practice learning environment before the practicum commences has been emphasised (van der Riet, Levett-Jones \& Courtney-Pratt 2018). Using mixed methods research involving 51 paediatric and mental health PRN students in Scotland, Millar, Conlon and McGirr (2017, p.47) also identified that 'the process of moving between different placement areas can make students feel unsettled, thereby compromising their learning'.

Similarly, a web-based questionnaire completed by 1,903 nursing students in Belgium, Cyprus, England, Finland, the Republic of Ireland, Italy, the Netherlands, Spain and Sweden found that learners acquired a better understanding of the RN role during a longer practicum (Warne et al 2010). Due to the pressures exerted on service provision by the COVID-19 pandemic, the Nursing and Midwifery Council (2020, p.7) [the UK's regulatory body for the discipline] recently agreed to permit undergraduate nursing students in either the second year or the first six months of their final programme year to receive 'ongoing learning and pastoral support in extended clinical placements' and thereby reflects a national move towards responding to concerns regarding the length of such practice learning provision; albeit one that may only be temporary. Arguably, the implementation of longer placements may be a critical weapon in strengthening clinical learning, enhancing learner satisfaction and reducing student stress and attrition. 
In China, a cross-sectional study involving 474 PRN students following completion of a general hospital sub-internship lasting six months found that 'the nursing students' level of role stress at the end of the first sub-internship was high' and that most felt they had been given unnecessary work in the clinical setting that was inconsistent with their role (Sun, Gao, Yang, Zang, \& Wang 2016, p.1). Using focus groups to examine the learning experiences of 90 baccalaureate PRN students in Iran, Sharif and Masoumi (2005, p.1) identified that 'nursing students were not satisfied with the clinical component of their education' and 'experienced anxiety as a result of feeling incompetent'; emotions that the researchers believed were intensified by these students perceiving a theory-practice gap in their programme. Learners disclosed that the initial period of a practicum was the most anxiety-generating element of each clinical experience; partly due to a fear of their making mistakes and suggested there were tensions with supervising nurses regarding the work they were given, since this was commonly comprised of basic nursing tasks which they believed would have been better delegated to non-registrant healthcare support workers [HCSWs]. Correspondingly, semi-structured interviews involving 7 second and third-year adult PRN students in Scotland who were assigned an Emergency Department practicum also indicated that most had high levels of stress and anxiety prior to the placement and felt inadequately prepared for the experience; fearing they would be unable to fulfil the expectations of RNs in the setting (Hunter, 2010).

A survey involving 125 nursing students in Saudi Arabia highlighted moving clinical placements and limited professional knowledge and skills as significant stressors. Moreover, the researchers identified learner relationships with teachers and hospital nursing staff as stress-provoking factors (Waled \& Badria 2019). Research involving nursing students in the Republic of Ireland using a questionnaire found that 'many students experience programme-related stressors' and that 'more than one-third also reported stressors related to relationships with clinical staff and clinical assessment of competence' (Timmins et al 2011, p.758); whilst a survey of 174 undergraduate nursing students in Northern Ireland highlighted that 'students generally had a less than positive clinical placement experience' (Shivers, Hasson \& Slater 2017, p.62). Clearly, if practicum experiences involve negative working relationships and cause PRN students to develop poor self-efficacy, the consequences may have an adverse effect on their stress levels as well as long-term negative implications for their professional performance.

\section{The 'Hidden Curriculum'}

MacMillan (in Eggertson 2013, p.24) suggests that the stress experienced by PRN students may be exacerbated by the 'hidden curriculum' they commonly encounter in clinical placements. Instead of being treated as partners in the healthcare team, she argues that those responsible for supervising and supporting such students during their placements 'often silence them when they raise issues or questions about something they have observed in a patient's care'; hence they 'receive an unspoken message: their job is to follow orders and procedure, not try to change the status quo'. MacMillan's claims in respect of Canadian nurse education were made without supporting empirical evidence, but in an earlier paper, Priest (2005) asserts that there is both research and anecdotal data from nursing students in this nation to support them.

This phenomenon may also be evident in the learning experiences of PRN students in other countries. An ethnographic case study in England by Allan, Smith and O'Driscoll (2011, p.847) concluded that two key elements of the hidden curriculum in practice learning are the expectations of trained staff that PRN students, despite their supernumerary status, should 'work while they learn and that on registration, they are expected to be competent to work immediately as registered nurses'. Semi-structured interviews involving Bruneian student nurses found that 'their status as students caused them stress in the clinical setting' and the researchers attributed this stress to the low ranking of such practitioners within the healthcare hierarchy (Burnard, Rahim, Hayes \& Edwards 2007, p.808).

Furthermore, in a systematic review and meta-synthesis of qualitative literature related to the experiences of nursing students in UK adult hospital settings, Thomas, Jack and Jinks (2012) identified that a notable minority of PRN students in the UK do not have nurturing and caring placements and experience less than positive relationships with clinicians. More recently, research involving the completion of a qualitative questionnaire by 77 nursing students in Finland concluded that being excluded from mainstream staff activity in a practicum can cause the learner to acquire a permanent negative professional self-image (Hemberg \& Sjoblom 2018); consequences that may have a significant harmful effect on the individual's future contribution to the provision of nursing care.

\section{Nurse Educators: Both a Solution and a Problem}

Nurse educators may help to prevent, or at least challenge, the hidden curriculum in practice learning 
environments and in so doing reduce the theory-practice gap. In Malaysia, a survey involving 142 student nurses, 54 RNs and 8 Nurse Tutors identified that students regarded supervision by clinical instructors as the most positive component of the practice learning environment (Chuan \& Bennet 2012). A longitudinal study in Australia involving interviews, surveys and field work observations with 28 second and third-year PRN students, 25 RNs, 6 Nurse Unit Managers and 4 Directors of Nursing also identified the value of effective clinical teachers. Indeed, student respondents often 'recounted positive interactions where the teacher engaged them in various activities and explained practices in detail' (Newton, Billett, Jolly \& Ockerby 2009 p.323). Moreover, a survey involving 310 nursing students in Oman showed interpersonal relationships with clinical teachers was a key dimension of their satisfaction with a practice learning environment (D'Souza, Karkada, Parahoo \& Venkatesaperuma 2017). Quantitative research in Italy examining the placement experiences of 597 nursing degree students, however, found wide variation in the reported quality of the tutorial relationship between nurse teachers and students (Tomietto, Comparcini, Saarikoski, Simonetti \& Cicolini 2014).

In Jordan, semi-structured interviews with 30 PRN students found that clinical instructors often seem to have received inadequate preparation for their role, failed to individualise student support and displayed limited evidence of communicating effectively with other academic staff to ensure consistency in educational provision during the programme (Saifan, Eid AbuRuz, \& Masa'deh 2015). A survey in Israel involving 200 RNs working as preceptors in both hospital and community settings also found that 'a considerable proportion of the preceptors feel inadequately prepared for their role' (Natan, Qeadan \& Egbaria 2014, p.1429). Similarly, a questionnaire completed by 34 RNs in Australia identified that some respondents did not have the qualification they were supporting students to obtain, that the university offered scant preparation for preceptors and provided little in the way of resources to help such staff fulfil their responsibilities in this additional role (Broadbent, Moxham, Sander, Walker \& Dwyer 2014).

Worse still, more recent evidence suggests nurse educators may even significantly contribute to PRN student stress. A questionnaire completed by 100 nursing students in Saudi Arabia indicated that working relationships with teachers and nursing staff were one of the highest sources of stress during clinical placements. These respondents largely attributed such stress to conflicting expectations, lack of guidance, unfair evaluations and a perceived discrepancy between theory and practice (Hamaideh, Al-Omari \& Al-Modallal 2017). Correspondingly, a study in Spain involving 69 PRN students and using a nursing stress questionnaire also identified relationships with tutors as one of the most powerful stressors experienced by learners (Gorostidi et al 2007). Moreover, in-depth interviews of 14 nursing students in Turkey by Arkan, Ordin and Yilmaz (2018) found not only were such teaching staff infrequent visitors to the clinical environment, but that their high expectations led some students to become demotivated and emotionally exhausted.

Evidence suggests that, in some instances, the conduct of practitioners assigned to teach, guide and support students in their practicum also leaves much to be desired. Semi-structured interviews with 16 nursing students in South Korea indicated that respondents often felt that 'the nurses were too busy to educate the students' during placements (Lee, Clarke \& Carson 2018, p.107); whilst in Trinidad and Tobago, results from a semi-structured questionnaire completed by 103 nursing students highlighted a range of negative learner perceptions regarding supervising nurses in clinical placements. Respondents suggested that they were perceived as just an 'extra pair of hands', ignored when they entered the practice setting and that some nurses got tired of helping them when there were competing demands on their time (Prescott-Carter \& Onuoha 2016). Furthermore, in Australia an online survey completed by 159 PRN students suggested many respondents believed nurses to whom they were assigned in a practicum were not interested in supporting them and that this led them to feel they were a burden (Walker et al, 2014).

More recently, a survey of 1,425 PRN students and follow-up unstructured interviews with 22 learners in England generated similar findings. Whilst respondents were eager to contribute to nursing care and acquire a sense of belonging within the clinical team, in some placements they reported feeling unsupported, ignored, treated as unpaid help and even bullied (Jack et al, 2018). Student stress exacerbated by interaction with staff designated to support their learning, however, is not unique to nursing. For example, research in Iran involving semi-structured interviews with 13 physiotherapy undergraduates identified a number of negative learning experiences on the programme which were attributed to their clinical training supervisor; including this academic disregarding their opinions during initial clinical evaluations, overlooking their knowledge and skills, delivering formal teaching sessions which were unrelated to their concurrent clinical placement, providing unfair evaluations of their performance and even humiliating them in front of others (Menatnia, Noorizadeh Dehkordi \& Dadgoo 2017).

It has long been argued that inter-disciplinary and inter-professional education may be a means by which to 
promote more integrated healthcare provision and strengthen relationships between different practitioner groups (McAllister et al 2014, Naylor et al 2016). Nevertheless, if providing inter-professional education risks harming student learning further as a result of nursing inadvertently acquiring those existing problems within the educational provision offered by other allied health professions, then evidently such change may do more harm than good in respect of the PRN student learning experience. Perhaps, therefore, nursing needs to address the problems associated with the conduct of some of its own educators before implementing such integrated education.

\section{Part-Time Study and Mature Nursing Student Stressors}

Since 1980, the number of mature students engaged in higher education within the UK has increased from approximately 10 percent to nearly 33 percent (McVitty \& Morris 2012). Nevertheless, James and Beck (2016, p.103) argue that 'despite changes in demographics and in policy rhetoric older learners still remain largely absent from debates about higher education'. The precise definition of a mature learner varies but is commonly described as between 21 and 25 years or older (Holt, Whitehead \& Budd 2018, Reid 2020). In the UK, part-time undergraduate demographics are significantly different to those of the full-time student population. Over 79 percent of these learners are more than 25 years old [compared with 13 percent of full-time undergraduates], 64 percent are female [compared with 56 percent of full-time learners] and 66 percent have family commitments [when most full-time undergraduates are single and have no children]. Part-time higher education students are also more likely to study subjects allied to medicine (Callender, Hopkin \& Wilkinson 2010, Callender, Jamieson \& Mason 2010, UK Commission for Employment \& Skills 2011).

Evidence suggests that part-time study can have additional negative social and psychological consequences. In the UK, completion rates for all part-time higher education courses are significantly lower than those for full-time programmes (Universities UK 2013). Butcher (2015, p.54) reports that some part-time undergraduates with concurrent employment must radically change their lifestyle to accommodate the additional demands that study makes on their time. These students also describe working and studying at the same time as 'like having two different personalities' and often seek to hide their student status from work colleagues. Given that McDaid (2009) discloses she and some of her colleagues received negative remarks from staff about their status on a part-time PRN programme, leading them to feel undervalued, such behaviour is perhaps understandable.

In Jamaica, a descriptive correlational design involving 20 part-time graduate nursing students found that over $73 \%$ of respondents reported a moderate or high level of stress during their programme (Brown, Anderson-Johnson \& McPherson 2016). Additionally, a survey in Scotland involving 113 third-year adult nursing students found that some of the greatest reported barriers preventing higher education diploma students from considering a transfer to a degree programme were 'the combined pressures of work, study and family stress' (Sheward 2005, p.153). Similarly, a questionnaire completed by 111 nursing undergraduates at a Brazilian university highlighted that the main stressors reported by students included inadequate time with family members and for leisure activities (de Souza et al, 2016). Given that 'the widening participation agenda has been encouraging mature students to go to university' and data suggests that one in four higher education students in the UK is a parent (White 2012, p.64), it seems reasonable to conclude that such tensions may be commonplace within the undergraduate PRN student population at many universities; especially for those completing part-time undergraduate study.

A survey by Nicholl and Timmins (2005, p.96) involving 70 part-time undergraduate nursing students at a university in the Republic of Ireland found that 'trying to balance their work commitments with the required study' was rated as their highest educational stressor. Further research in the Republic of Ireland by Evans, Brown, Timmins and Nicholl (2007, p.734) employing a questionnaire completed by 132 respondents undertaking a part-time degree course for qualified nurses in two academic institutions identified this challenge as the second highest mean stressor after 'preparing assignments for submission'. Moreover, on a part-time higher education diploma PRN programme in England, O'Driscoll, Smith and Magnusson (2009, p.213) also discovered that 'placements were identified by students as a time when tension between home, student and employment rolls may become particularly high'.

\section{Transitional Challenges}

A survey of 275 nursing students in the Czech Republic and Slovakia found that 'experienced nursing students perceived higher levels of stress than novice students' and that this stress was mainly associated with clinical experiences (Gurková \& Zeleníková 2018, p.4). Similarly, longitudinal quantitative research involving 112 PRN students in Wales over the duration of their programme found that levels of self-reported stress and self-esteem were significantly different at various stages of nurse training. Stress was reported to be 'highest at the beginning 
of the third year', 'self-esteem levels were lowest at the end of training' and when these students had completed their programme and were applying for jobs, their stress levels reduced (Edwards, Burnard, Bennett \& Hebden 2010, p.82). Although the researchers did not attribute these findings to any specific cause, they acknowledged the view that nursing students in their final year of training may be exposed to greater stressors and struggle to regard themselves as individuals who are sufficiently well-prepared to soon become RNs. These observations, however, are supported by research indicating that final year PRN students in Spain attribute much of their stress to a perceived 'lack of competence, uncertainty and impotence' (Gorostidi et al 2007, p.777). Furthermore, recent research in Israel involving 892 second, third and fourth-year PRN students also highlighted that stress was commonly related to learners feeling they had received inadequate training and lacked crucial nursing knowledge, although the researchers found such stressors were greatest amongst second-year students (Admi, Moshe-Eilon, Sharon \& Mann 2018).

Qualitative research by Draper et al (2014, p.1308) involving semi-structured telephone interviews with 17 alumni of a part-time, UK-wide PRN programme, all of whom were non-registrant HCSWs concurrent with their nursing student role, highlighted that there were 'challenges associated with the stages of transition from HCSW to student to registered practice'. Respondents identified the most significant challenges they encountered as dealing with resentment and jealousy from those non-registrant staff with whom the newly qualified nurses had earlier been peers, managing the frustration of moving between a student and HCSW role [since the skills they were permitted to use in each varied] and asserting their need for supernumerary practice learning as nursing students. Overall, these alumni believed that becoming RNs via this PRN course was harder than doing so through a more traditional programme because it demanded more self-discipline, self-management and self-motivation.

In respect of part-time nursing programmes it has been argued that, 'managers and nurses need to work together to devise flexible working options that will maintain organizational goals while facilitating nurses to study' (Timmins \& Nicholl 2005, p.481); whilst 'nurse educators need to address student needs to handle these stressors effectively' (Alzayyat \& Al-Gamal 2014, p.412). Given the transitional challenges experienced by PRN students that are evidenced within various research studies, such actions appear not only to be logical and justifiable, but highly desirable.

\section{Conclusions and a Way Forward}

The evidence captured within this Critical Realist review suggests that nursing student stress is indeed an enduring, complex, worldwide phenomenon affected by a wide range of educational, social, environmental, intrapersonal and interpersonal variables. Specifically, such variables include the mode of nursing study undertaken, the academic and placement expectations of the course, competing family, programme and work demands, the learner's self-concept and perceived preparedness for future practice, tensions between professional learning and delivering nursing care, a student's sense of belonging within a practicum, their relationship with clinical and teaching staff and transitional challenges. Given the wide range of factors that may adversely affect the nursing student experience and numerous negative reports from such learners it seems, therefore, nursing still has much to do if it is to reduce stress within PRN programmes, address staff shortages and more effectively prepare itself for the future challenges all healthcare disciplines will inevitably face.

This review also suggests that little attention has so far been given either to the experiences of stress from the perspective of mature PRN students or the potential impact of different models of practice learning on levels of nursing student stress; despite clinical placements being identified as a key stressor for such learners, concerns expressed by some nurse researchers regarding short practice learning experiences exacerbating student stress and adversely affecting clinical learning and the increasing need for nursing to widen the traditional student demographic if it is to effectively address a global shortage of RNs. The paucity of specific research in these areas is therefore part of the rationale which underpins the authors' current involvement in mixed methods research, driven by the principles of Critical Realism, which is examining the impact of two practicum models on the learning experiences of mature PRN students. These researchers therefore look forward to extending the body of knowledge within this field in due course, making recommendations for the development of future nursing curricula congruent with Critical Realist philosophy and in so doing contribute to addressing PRN student retention and staffing issues within the discipline.

\section{References}

Admi, H., Moshe-Eilon, Y., Sharon, D., \& Mann, M. (2018). Nursing students' stress and satisfaction in clinical practice along different stages: A cross-sectional study. Nurse Education Today, 68, 86-92. https://doi.org/10.1016/j.nedt.2018.05.027 
Allan, H., Smith, P., \& O'Driscoll, M. (2011). Experiences of supernumerary status and the hidden curriculum in nursing: a new twist in the theory-practice gap?. Journal of Clinical Nursing, 20, 847-855. https://doi.org/10.1111/j.1365-2702.2010.03570.x

Alzayyat, A., \& Al-Gamal, E. (2014). A review of the literature regarding stress among nursing students during their clinical education. International Nursing Review, 61, 406-415. https://doi.org/10.1111/inr.12114

Bergin, M., Wells, J., \& Owen, S. (2008). Critical realism: a philosophical framework for the study of gender and mental health. Nursing Philosophy, 9(3), 169-179. https://doi.org/10.1111/j.1466-769X.2008.00358.x

Bhaskar, R. (2008). A Realist Theory of Science. Taylor \& Francis e-Library Edition, Abingdon, Routledge.

Bisman, J. (2010). Postpositivism and Accounting Research: A (Personal) Primer on Critical Realism. Australasian Accounting Business and Finance Journal, 4(4), 3-25.

Boath, E., Jinks, A., Thomas, N., Thompson, R., Evans, J., O’Connell, P., \& Taylor, L. (2016). Don't go with the 'FLO' - a student mobile texting service to enhance nursing student retention. Nurse Education Today, 45, 80-86. https://doi.org/10.1016/j.nedt.2016.06.019

Bonine, K., \& Oh, K. (2006). Critical Evaluation of a Published Paper. Retrieved from http://eebweb.arizona.edu/courses/Ecol437/CriticallyEvaluatingScientificPapers2006.doc

Boychuk Duchscher, J. (2009). Transition shock: the initial stage of role adaptation for newly graduated Registered Nurses. Journal of Advanced Nursing, 65(5), 1103-1113. https://doi.org/10.1111/j.1365-2648.2008.04898.x

Broadbent, M., Moxham, L., Sander, T., Walker, S., \& Dwyer, T. (2014). Supporting bachelor of nursing students within the clinical environment: Perspectives of preceptors. Nurse Education in Practice, 14, 403-409. https://doi.org/10.1016/j.nepr.2013.12.003

Brown, K., Anderson-Johnson, P., \& Norman McPherson, A. (2016). Academic-related stress among graduate students in nursing in a Jamaican school of nursing. Nurse Education in Practice, 20, 117-124. https://doi.org/10.1016/j.nepr.2016.08.004

Buchan, J., Charlesworth, A., Gershlick, B., \& Seccombe, I. (2019). A critical moment: NHS staffing trends, retention and attrition. London, The Health Foundation.

Burnard, P., Edwards, D., Bennett, K., Thaibah, H., Tothova, V., Baldacchino, D., ... Mytevelli, J. (2008). A comparative, longitudinal study of stress in student nurses in five countries: Albania, Brunei, the Czech Republic, Malta and Wales. Nurse Education Today, 28, 134-145. https://doi.org/10.1016/j.nedt.2007.04.002

Burnard, P., Rahim, H., Hayes, D., \& Edwards, D. (2007). A descriptive study of Bruneian student nurses' perceptions of stress. Nurse Education Today, 27, 808-818. https://doi.org/10.1016/j.nedt.2006.11.002

Butcher, J. (2015). Listen to part-time learners and smart policy will follow. In N. Hillman (Ed.), It's the finance, stupid! The decline of part-time higher education and what to do about it. Oxford, Higher Education Policy Institute.

Callender, C., Hopkin, R., \& Wilkinson, D. (2010). Futuretrack: part-time students career decision-making and career development of part-time higher education students. Manchester, Higher Education Careers Services Unit.

Callender, C., Jamieson, A., \& Mason, G. (2010). The Supply of Part-Time Higher Education in the UK. London, Universities UK.

Chan, A., Tang, F., Choi, K., Liu, T., \& Taylor-Pilae, R. (2018). Clinical learning experiences of nursing students using an innovative clinical partnership model: A non-randomized controlled trial. Nurse Education Today, 68, 121-127. https://doi.org/10.1016/j.nedt.2018.06.001

Chuan, O., \& Barnett, T. (2012). Student, tutor and staff nurse perceptions of the clinical learning environment. Nurse Education in Practice, 12, 192-197. https://doi.org/10.1016/j.nepr.2012.01.003

Clark, A. (2008). Critical Realism. In L. Given (Ed.), The Sage Encyclopedia of Qualitative Research Methods. Thousand Oaks, Sage.

Clegg, S. (2005). Evidence-Based Practice in Educational Research: A Critical Realist Critique of Systematic Review. British Journal of Sociology of Education, 26(3), 415-428. https://doi.org/10.1080/01425690500128932 
Cust, F. (2020). Nurses are leaving and students are unsupported-drastic measures are required. Nursing Times. Retrieved

https://www.nursingtimes.net/opinion/nurses-are-leaving-and-students-are-unsupported-drastic-measures-ar e-required-13-01-2020/

D’Souza, M., Karkada, S., Parahoo, K., \& Venkatesaperuma, R. (2017). Perception of and satisfaction with the clinical learning environment among nursing students. Nurse Education Today, 35, 833-840. https://doi.org/10.1016/j.nedt.2015.02.005

De Souza, V., Costa, M., Rodrigues, A., Bevilaqua, J., Inoue, K., de Oliveira, J., \& Matsuda, L. (2016). Stress among nursing undergraduate students of a Brazilian public university. Investigación y Educación en Enfermeria, 34(3), 518-527. https://doi.org/10.17533/udea.iee.v34n3a11

Edgley, A., Stickley, T., Timmons, S., \& Meal, A. (2016). Critical realist review: exploring the real, beyond the empirical. Journal of Further and Higher Education, 40(3), 316-330. https://doi.org/10.1080/0309877X.2014.953458

Edwards, D., Burnard, P., Bennett, K., \& Hebden, U. (2010). A longitudinal study of stress and self-esteem in student nurses. Nurse Education Today, 30, 78-84. https://doi.org/10.1016/j.nedt.2009.06.008

Evans, W., Brown, G., Timmins, F., \& Nicholl, H. (2007). An exploratory study identifying the programme related stressors amongst qualified nurses completing part-time degree courses. Nurse Education Today, 27, 731-738. https://doi.org/10.1016/j.nedt.2006.10.015

Flott, E., \& Linden, L. (2016). The clinical learning environment in nursing education: a concept analysis. Journal of Advanced Nursing, 72(3), 501-513. https://doi.org/10.1111/jan.12861

Fornés-Vives, J., Garcia-Banda, G., Frias-Navarr, D., \& Rosales-Viladrich, G. (2016). Coping, stress, and personality in Spanish nursing students: A longitudinal study. Nurse Education Today, 36, 318-323. https://doi.org/10.1016/j.nedt.2015.08.011

Golos, A., \& Tekuzener, E. (2019). Perceptions, expectations and satisfaction levels of occupational therapy students prior to and after practice placement and comparison of practice placement models. BMC Medical Education, 19(1), 1-8. https://doi.org/10.1186/s12909-019-1762-0

Gorostidi, X., Egilegor, X., Erice, M., Iturriotz, M., Garate, I., Lasa, M., \& Cascante, X. (2007). Stress sources in nursing practice. Evolution during nursing training. Nurse Education Today, 27, 777-787. https://doi.org/10.1016/j.nedt.2006.10.017

Govender, P., Mkhabela, S., Hlongwane, M., Jalim, K., \& Jetha, C. (2015). OT student's experiences of stress and coping. South African Journal of Occupational Therapy, 45(3), 34-39. https://doi.org/10.17159/2310-3833/2015/v45n3/a7

Gurková, E., \& Zeleníková, R. (2018). Nursing students' perceived stress, coping strategies, health and supervisory approaches in clinical practice: A Slovak and Czech perspective. Nurse Education Today, 65, 4-10. https://doi.org/10.1016/j.nedt.2018.02.023

Hamaideh, S., Al-Omari, H., \& Al-Modallal, H. (2017). Nursing students' perceived stress and coping behaviors in clinical training in Saudi Arabia. Journal of Mental Health, 26(3), 197-203. https://doi.org/10.3109/09638237.2016.1139067

Health Education England. (2015). Growing Nursing Numbers, Literature review on nurses leaving the NHS. London, Health Education England. Retrieved from https://www.hee.nhs.uk/sites/default/files/documents/Nurses\%20leaving\%20practice\%20-\%20Literature\%2 0Review.pdf

Health \& Safety Executive. (2020). Work-related stress and how to tackle it. Retrieved from https://www.hse.gov.uk/stress/what-to-do.htm\#: :text=HSE\%20defines\%20stress\%20as\%20\%27the,with\% 20pressures\%20and\%20other\%20issues.\&text=Providing\%20planning\%2C\%20training\%20and\%20suppor t,and\%20bring\%20stress\%20levels\%20down

Hemberg, J., \& Sjoblom, M. (2018). Invitation as the Cornerstone for Supervision in Nursing Clinical Placement. International Journal of Caring Sciences, 11(2), 687-696.

Higuchi, D., \& Echigo, A. (2016). Characteristics of coping strategies and the relationships between coping strategies and stress reactions in physical therapy students during clinical practice. The Journal of Physical Therapy Science, 28, 2867-2870. https://doi.org/10.1589/jpts.28.2867 
Holt, P., Whitehead, B., \& Budd, C. (2018). Maintaining student enrolment after the removal of bursaries. Nursing Times, 114(7), 56-59.

Jack, K., Hamshire, C., Harris, W., Langan, M., Barrett, N., \& Wibberley, C. (2018). “My mentor didn’t speak to me for the first four weeks": Perceived Unfairness experienced by nursing students in clinical practice settings. Journal of Clinical Nursing, 27, 929-938. https://doi.org/10.1111/jocn.14015

James, N., \& Beck, V. (2016). The perils of disregarding older learners in higher education. HE: Transforming lives through life-wide-learning?. Conference, April 27th-28th, Milton Keynes. UK, The Open University.

Kuhlmann, S., Huss, M., Burger, A., \& Hammerle, F. (2016). Coping with stress in medical students: results of a randomized controlled trial using a mindfulness-based stress prevention training (MediMind) in Germany. BMC Medical Education, 16. https://doi.org/10.1186/s12909-016-0833-8

Laal, M., \& Aliramaie, N. (2010). Nursing and Coping with Stress. International Journal of Collaborative Research on Internal Medicine \& Public Health, 2(50), 168-181.

Labrague, L. (2013). Stress, Stressors, and Stress Responses of Student Nurses in a Government Nursing School. Health Science Journal, 7(4), 424-435.

Labrague, L., McEnroe-Petitte, D., Papathanasiou, I., Edet, O., Tsaras, K., Leocadio, M., ... Velacaria, P. (2018). Stress and coping strategies among nursing students: an international study. Journal of Mental Health, 27(5), 402-408. https://doi.org/10.1080/09638237.2017.1417552

Lee, J., Clarke, C., \& Carson, M. (2018). Nursing students' learning dynamics and influencing factors in clinical contexts. Nurse Education in Practice, 29, 103-109. https://doi.org/10.1016/j.nepr.2017.12.003

Lyon, B. (2012). Stress, coping and health: a conceptual overview (Update). In V. Hill Rice (Ed.), Handbook of Stress, Coping and Health. Implications for Nursing Research, Theory and Practice. Thousand Oaks, Sage.

MacMillan, K., \& Eggertson, L. (2013). The Gap between Clinical Practice and Education. Canadian Nurse, 109(7), 22-26.

Madhavanpraphakaran, G., Shukri, R., \& Balachandran, S. (2014). Preceptors' Perceptions of Clinical Nursing Education. The Journal of Continuing Education in Nursing, 45(1), 28-34. https://doi.org/10.3928/00220124-20131223-04

Maldarez, A., Hobson, A., Tracey, L., \& Kerr, K. (2007). Becoming a student teacher: core features of the

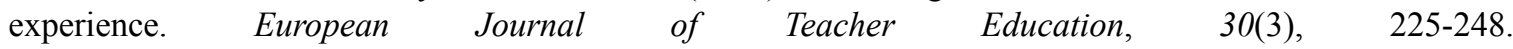
https://doi.org/10.1080/02619760701486068

McAllister, M., Statham, D., Oprescu, F., Schmidt, T., Boulter, C., Taylor, P., ... Raith, L. (2014). Mental health interprofessional education for health professions students: bridging the gaps. The Journal of Mental Health Training, Education and Practice, 9(1), 35-45. https://doi.org/10.1108/JMHTEP-09-2012-0030

McDaid, E. (2009). Full-time commitment. Nursing Standard, 23(43), 61. https://doi.org/10.7748/ns.23.43.61.s53

McEvoy, P., \& Richards, D. (2006). A critical realist rationale for using a combination of quantitative and qualitative methods. Journal of Research in Nursing, 11(1), 66-78. https://doi.org/10.1177/1744987106060192

McGhee, P., \& Grant, P. (2017). Applying critical realism in spirituality at work research. Management Research Review, 40(8), 845-869. https://doi.org/10.1108/MRR-05-2016-0124

McVitty, D., \& Morris, K. (2012). Never Too Late to Learn. Mature students in higher education. London, Million + and National Union of Students.

Menatnia, F., Noorizadeh Dehkordi, S., \& Dadgoo, M. (2017). Problems of Clinical Education from the Viewpoints of the Physiotherapy Students in Iran Universities. Journal of Modern Rehabilitation, 11(4), 245-250.

Millar, L., Conlon, M., \& McGirr, D. (2017). Students' perspectives of using the hub and spoke model to support and develop learning in practice. Nursing Standard, 32(9), 41-49. https://doi.org/10.7748/ns.2017.e10389

Natan, M., Qeadan, H., \& Egbaria, W. (2014). The commitment of Israeli nursing preceptors to the role of preceptor. Nurse Education Today, 34, 1425-1429. https://doi.org/10.1016/j.nedt.2014.04.011

Naylor, C., Das, P., Ross, S., Honeyman, M., Thompson, J., \& Gilburt, H. (2016). Bringing together physical and mental health, a new frontier for integrated care. London, The King's Fund. 
https://doi.org/10.1016/j.ijnurstu.2006.05.017

Newton, J., \& McKenna, L. (2007). The transitional journey through the graduate year: A focus group study. International Journal of Nursing Studies, 44, 1231-1237. https://doi.org/10.1111/j.1473-6861.2009.00229.x

Newton, J., Billett, S., Jolly, B., \& Ockerby, C. (2009). Lost in translation: barriers to learning in health professional clinical education. Learning in Health \& Social Care, 8(4), 315-327.

Nicholl, H., \& Timmins, F. (2005). Programme-related stressors among part-time undergraduate nursing students. Journal of Advanced Nursing, 50(1), 94-100. https://doi.org/10.1111/j.1365-2648.2004.03352.x

Nursing \& Midwifery Council. (2020). NMC response to the Covid-19 emergency. Item 6 NMC/20/20 25 March. London, Nursing and Midwifery Council. Retrieved from https://www.nmc.org.uk/globalassets/sitedocuments/councilpapersanddocuments/council-2020/item-6-nmcresponse-to-the-covid-19-emergency.pdf

O'Donovan, R., Doody, O., \& Lyons, R. (2013). The effect of stress on health and its implications for nursing. British Journal of Nursing, 22(16), 969-973. https://doi.org/10.12968/bjon.2013.22.16.969

O'Driscoll, M., Smith, P., \& Magnusson, C. (2009). Evaluation of a part-time adult diploma nursing programme-'Tailor-made' provision?. Nurse Education Today, 29, 208-216. https://doi.org/10.1016/j.nedt.2008.08.006

O'Mahoney, J., \& Vincent, S. (2014). Chapter 1. Critical Realism as an empirical project: a beginner's guide. In P. Edwards, J. O'Mahoney, \& S. Vincent (Eds.), Studying organizations using critical realism, a practical guide. Oxford University Press. https://doi.org/10.1093/acprof:oso/9780199665525.003.0001

Ord, K., \& Nuttall, J. (2016). Bodies of knowledge: The concept of embodiment as an alternative to theory/practice debates in the preparation of teachers. Teaching and Teacher Education, 60, 355-362. https://doi.org/10.1016/j.tate.2016.05.019

Parlour, R., \& McCormack, B. (2012). Blending critical realist and emancipatory practice development methodologies: making critical realism work in nursing research. Nursing Inquiry, 19(4), 308-321. https://doi.org/10.1111/j.1440-1800.2011.00577.x

Parpio, Y., Malik, S., Punjani, N., \& Farooq, S. (2013). Critical Realism: Tenets and Application in Nursing. International Journal of Innovative Research \& Development, 2(11), 490-493.

Patomaki, H., \& Wight, C. (2000). After Postpositivism? The Promises of Critical Realism. International Studies Quarterly, 44, 213-237. https://doi.org/10.1111/0020-8833.00156

Prescott-Carter, K., \& Onuoha, P. (2016). Nursing Students' Levels of Satisfaction on Their Clinical Experiences at a Major Caribbean Hospital. International Journal of Advanced Research, 4(4), 1036-1050. https://doi.org/10.21474/IJAR01/195

Priest, A. (2005). Student Reps Turn Ideas into Action. Nursing BC, 37(4), 21-25.

Rafati, F., Esmat, E., Sabzevari, S., \& Dehghan-Nayeri, N. (2017). Coping strategies of nursing students for dealing with stress in clinical setting: A qualitative study. Electronic Physician, 9(12), 6120-6128. https://doi.org/10.19082/6120

Rahmann, N., Ismail, S., Seman, T., Rosli, N., Jusoh, S., Islam, M., \& Haque, M. (2014). Stress among preclinical medical students of Universiti Sultan Zainal Abidin. Optimising Interprofessional Education (IPE) For Healthcare, 9th International Medical Education Conference. International Medical University, Kuala Lumpur, 11 - 13 March 2014. IMEC.

Reid, W. (2020). Memorandum to Regional Directors. London, Health Education England.

Rudman, A., \& Gustavsson, J. (2012). Burnout during nursing education predicts lower occupational preparedness and future clinical performance: A longitudinal study. International Journal of Nursing Studies, 49, 988-1001. https://doi.org/10.1016/j.ijnurstu.2012.03.010

Saifan, A., Eid AbuRuz, M., \& Masa'deh, R. (2015). Theory Practice Gaps in Nurse Education: A Qualitative Perspective. Journal of Social Sciences, 11(1), 20-29. https://doi.org/10.3844/jssp.2015.20.29

Shaban, I., Khater, W., \& Akhu-Zaheya, L. (2012). Undergraduate nursing students' stress sources and coping behaviours during their initial period of clinical training: A Jordanian perspective. Nurse Education in Practice, 12, 204-209. https://doi.org/10.1016/j.nepr.2012.01.005

Shajimon, P., \& Soon-Chean, P. (2018). Changing research methodology: Two case studies of critical realism 
informing social work doctoral research. Aotearoa New Zealand Social Work, 30(1), 65-70. https://doi.org/10.11157/anzswj-vol30iss1id426

Sharif, F., \& Masoumi, S. (2005). A qualitative study of nursing student experiences of clinical practice. BMC Nursing, 4(6), 1-7. https://doi.org/10.1186/1472-6955-4-6

Sheward, L. (2005). The Path to Nurse Registration. Doctoral Thesis, Strathclyde University, Glasgow, UK. Retrieved from http://www.bldss.bl.uk/

Shivers, E., Hasson, F., \& Slater, P. (2017). Pre-registration nursing student's quality of practice learning: Clinical learning environment inventory (actual) questionnaire. Nurse Education Today, 55, 58-64. https://doi.org/10.1016/j.nedt.2017.05.004

Siddiqi, F., Azim, M., Babur, M., Osama, M., Waheed A., \& Memon, A. (2019). Psychological Stress and Satisfaction with Life among Physical Therapy Students of Rawalpindi/Islamabad, Pakistan. Journal of Pakistan Medical Association, 69(7).

Sparacino, L. (2015). Faculty's Role in Assisting New Graduate Nurses' Adjustment to Practice. International Journal of Nursing, 2(2), 37-46. https://doi.org/10.15640/ijn.v2n2a5

Stecker, T. (2004). Well-being in an academic environment. Medical Education, 38, 465-478. https://doi.org/10.1046/j.1365-2929.2004.01812.x

Stricklin, K., \& Tingle, B. (2016). Using Online Education to Transition Teaching Assistants to Teacher Certification: Examining the Differences Between Teacher Education Programs. American Journal of Distance Education, 30(3), 192-202. https://doi.org/10.1080/08923647.2016.1192840

Sun, L., Gao, Y., Yang, J., Zang, X., \& Wang, Y. (2016). The impact of professional identity on role stress in nursing students: A cross-sectional study. International Journal of Nursing Studies, 63, 1-8. https://doi.org/10.1016/j.ijnurstu.2016.08.010

Tambag, H., \& Can, R. (2018). The Resilience Levels in Nursing and Health Sciences Students. International Journal of Caring Sciences, 11(3), 1509-1515.

Terry, K. (2013). The competency landscape: a critical realist exploration of the ways nurses understand and utilise competency standards. Doctoral thesis, University of Tasmania, Hobart. Retrieved from https://eprints.utas.edu.au/17166/.

Thomas, J., Jack, B., \& Jinks, A. (2012). Resilience to care: A systematic review and meta-synthesis of the qualitative literature concerning the experiences of student nurses in adult hospital settings in the UK. Nurse Education Today, 32, 657-664. https://doi.org/10.1016/j.nedt.2011.09.005

Timmins, F., \& Nicholl, H. (2005). Stressors associated with qualified nurses undertaking part-time degree programmes - some implications for nurse managers to consider. Journal of Nursing Management, 13, 477-482. https://doi.org/10.1111/j.1365-2934.2005.00547.x

Timmins, F., Corroon, A., Byrne, G., \& Mooney, B. (2011). The challenge of contemporary nurse education programmes. Perceived stressors of nursing students: mental health and related lifestyle issues. Journal of Psychiatric and Mental Health Nursing, 18, 758-766. https://doi.org/10.1111/j.1365-2850.2011.01780.x

Tomietto, M., Comparcini, D., Saarikoski, M., Simonetti, V., \& Cicolini, G. (2014). Multilevel perspectives in clinical learning environments' assessment: An insight on levels involved in planning nursing education. Journal of Nurse Education and Practice, 4(12), 42-50. https://doi.org/10.5430/jnep.v4n12p42

UK Commission for Employment and Skills. (2011). The impact of higher education for part-time students. Evidence Report 36. London, UK Commission for Employment and Skills.

Universities UK. (2013). The power of part-time. Review of part-time and mature higher education. London, Universities UK.

Urwin, S., Stanley, R., Jones, M., Gallagher, A., Wainwright, P., \& Perkins, A. (2010). Understanding student nurse attrition: Learning from the literature. Nurse Education Today, 30, 202-207. https://doi.org/10.1016/j.nedt.2009.07.014

Van der Riet, P., Levett-Jones, T., \& Courtney-Pratt, H. (2018). Nursing students' perceptions of a collaborative clinical placement model: A qualitative descriptive study. Nurse Education in Practice, 30, $42-47$. https://doi.org/10.1016/j.nepr.2018.02.007

Waled, A., \& Badria, M. (2019). Nursing students' stress and coping strategies during clinical training in KSA. 
Journal of Taibah University Medical Sciences, 14(2), 116-122. https://doi.org/10.1016/j.jtumed.2019.02.002

Walker, S., Dwyer, T., Broadbent, M., Moxham, L., Sander, T., \& Edwards, K. (2014). Constructing a nursing identity within the clinical environment: The student nurse experience. Contemporary Nurse, 49, 103-112. https://doi.org/10.1080/10376178.2014.11081960

Warne, T., Johansson, U., Papastavrou, E., Tichelaar, E., Tomietto, M., Van den Bossche, K., ... Saarikoski, M. (2010). An exploration of the clinical learning experience of nursing students in nine European countries. Nurse Education Today, 30, 809-815. https://doi.org/10.1016/j.nedt.2010.03.003

Weurlander, M., Lonn, A., Seeberger, A., Broberger, E., Hult, H., \& Wernerson, A. (2018). How do medical and nursing students experience emotional challenges during clinical placements?. International Journal of Medical Education, 9, 74-82. https://doi.org/10.5116/ijme.5a88.1 f80

White, S. (2012). When the going gets tough. Nursing Standard, 26(38), 64. https://doi.org/10.7748/ns2012.05.26.38.64.p8416

Williams, L., Rycroft-Malone, J., \& Burton, C. (2016). Bringing critical realism to nursing practice: Roy Bhaskar's contribution. Nursing Philosophy, 18(2), e12130. https://doi.org/10.1111/nup.12130

Willis, G. (2015). Raising the Bar. Shape of Caring: A Review of the Future Education and Training of Registered Nurses and Care Assistants. Leeds. Health Education England/Nursing \& Midwifery Council.

\section{Copyrights}

Copyright for this article is retained by the author(s), with first publication rights granted to the journal.

This is an open-access article distributed under the terms and conditions of the Creative Commons Attribution license (http://creativecommons.org/licenses/by/4.0/). 